\title{
Overall mental distress and health-related quality of life after solid-organ transplantation: results from a retrospective follow-up study
}

\author{
Andreas Baranyi ${ }^{*}$, Till Krauseneck ${ }^{2}$ and Hans-Bernd Rothenhäusler ${ }^{1,2}$
}

\begin{abstract}
Background: Our retrospective follow-up study aimed to explore the degree of overall mental distress in a cohort of solid-organ transplantation (SOT) recipients after liver, heart or lung transplantation. Furthermore, we investigated how overall mental distress is linked to health-related quality of life.

Methods: 123 SOT patients treated during the study period were enrolled in this investigation at a mean of 24.6 months ( $\mathrm{SD}=11.6)$ after transplantation. Before transplantation, the Transplant Evaluation Rating Scale (TERS) was used to classify the level of adjustment in psychosocial functioning among transplantation candidates. After transplantation, recipients completed a research battery, which included the SCL-90-R, and the SF-36.

Results: 39 (31.7\%) transplantation recipients had clinically significant overall mental distress as measured on the Global Severity Index of the SCL-90-R. Obsessive-compulsive symptoms (92.3\%), somatization symptoms (87.2\%), anxiety symptoms (84.6\%), depression symptoms (82.1\%) and phobic anxiety symptoms (69.2\%) were a frequent finding.

Transplantation recipients with overall mental distress had significant lower levels of adjustment in psychosocial functioning before transaplantation than those without overall mental distress as measured in the TERS.

Transplantation-related overall mental distress symptomatology was associated with maximal decrements in health-related quality of life.

Conclusion: Transplantation recipients may face major transplantation- and treatment-related overall mental distress and impairments to their health-related quality of life. Further, overall mental distress is a high-risk factor in intensifying impairments to patients' overall quality of life.
\end{abstract}

Keywords: Solid-organ transplantation, Overall mental distress, Health-related quality of life

\section{Background}

Great achievements have been made in the field of transplantation surgery over the past decades [1]. However, these usually life-saving interventions also present those affected with stressful experiences and great demands that not infrequently also trigger consequent psychiatric illnesses. Thus affective illnesses, maladjustment and severe anxiety have been diagnosed in $19-54 \%$ of patients during psychiatric evaluation processes [2-11].

\footnotetext{
* Correspondence: Andreas.Baranyi@klinikum-graz.at

${ }^{1}$ Department of Psychiatry, University of Medicine of Graz, Auenbruggerplatz 31, 8036, Graz, Austria

Full list of author information is available at the end of the article
}

In the assessment of outcomes following solid-organ transplantation, the transplantation's influence on psychic health and well-being is increasingly moving into the foreground $[1,7,12-17]$. A number of outcome studies showed that solid-organ transplantation is associated with improvements in health-related quality of life relative to the pretransplant period, but without restoring the health status levels described in the general population [10]. Earlier investigations showed a significant connection between psychiatric morbidity and impaired health-related quality of life [3].

The transplantation itself and the intensive care unit stay might be traumatic stressors that decrease healthrelated quality of life and can trigger overall mental 
distress. The term overall mental distress is widely used by mental health practitioners, to summarize a range of symptoms and experiences of a person's internal life that are commonly held to be confusing, troubling, or out of the ordinary. Overall mental distress has a wider scope than the related term mental illness. Thus mental illness refers to a specific set of medically defined conditions. In contrast a person in overall mental distress may display psychiatric symptoms such as depression, anxiety, confused emotions, hallucination or rage, without necessarily actually being ill in a psychiatric sense [18-20].

\section{Aims of the study}

Our retrospective follow-up study aimed to explore the degree of overall mental distress in a cohort of solidorgan transplantation recipients after liver, heart or lung transplantation. Furthermore, we investigated how overall mental distress is linked to health-related quality of life. The well-validated Transplant Evaluation Rating Scale (TERS) [21] is well established to classify the level of adjustment in psychosocial functioning among transplantation candidates. However, it is not proof of wheter pretransplant evaluation based on the Transplant Evaluation Rating Scale can help in indicating patients who are at high risk of posttransplant overall mental distress and impairments in health-related quality of life. This research question is another research aim of this study. Furthermore, factors that are described in the literature as potential contributing or associated factors to overall mental distress and impairments in health-related quality of life such as substance abuse (benzodiazepines, alcohol abuse), postoperative medical complications, social support or medical complications are considered [10].

\section{Method}

\section{Subjects and procedure}

During the study period a total of 280 patients underwent transplantation at the Transplantation Center of the Klinikum Grosshadern, Ludwig-Maximilians-University, Munich, Germany.

Before transplantation, the psychometric observerrating scale Transplant Evaluation Rating Scale (TERS) [21] was used to classify the level of adjustment in psychosocial functioning among solid-organ transplantation candidates. 65 of these 280 patients died before our retrospective follow-up study started. 215 eligible transplantation recipients were contacted by experienced psychiatrists and were asked to complete a research battery, which included an author-compiled clinical questionnaire, the SCL-90-R [22,23] and the Medical Outcome Study Form (SF-36) [24]. 123 transplantation recipients returned the questionnaires, at a mean of 24.9 months $(\mathrm{SD}=11.9)$ after transplantation. The SF-36 data were compared with data from normative population whose individuals were drawn at random with respect to age and gender from a large data base $(n=3000)$ used for the validation of the SF-36 in Germany.

Collected transplantation characteristics were the indications for heart transplantation (ischemic or dilated cardiomyopathy), orthotopic liver transplantation (alcoholic liver disease, infectious hepatitis, primary biliary cirrhosis, malignancy or other), and lung transplantation (emphysema and chronic obstructive pulmonary disease, pulmonary fibrosis, pulmonary hypertension or other). Postoperative medical complications, acute rejections and a history of retransplantation were observed.

\section{Psychometric tests}

Before solid-organ transplantation the transplantation candidates were evaluated by experienced consultationliaison psychiatrists using the psychometric observerrating TERS [21].

The TERS scale classifies the level of adjustment in psychosocial functioning among transplantation candidates and covers the different dimensions of psychosocial functions (pre-existing psychiatric morbidity, substance abuse, compliance, coping strategies, cognitive performance). The total sum reflects the current level of psychosocial functioning of the particular transplantation candidate. The higher the score, the worse the current level of psychosocial functioning.

After transplantation, an author-compiled questionnaire was used to obtain information about the patient and transplantation characteristics. Demographic variables included age, gender, years of education and/or vocational training, employment and marital status at the time of psychiatric assessment. The patient's employment status was categorized as paid work (full- or parttime) or no paid work (disability, retired, unemployed). Marital status was categorized as married, single, divorced, or widowed. Further, preoperative chronic benzodiazepine consumption and preoperative alcohol abuse were recorded.

The Symptom Check List (SCL-90-R) [22,23] is a well-researched and frequently used multidimensional self-rating 90-item scale to screen for a broad range of psychological problems. Each of the 90 items is rated on a five-point Likert scale ranging from "not at all" to "extremely" relating to distress. The nine primary symptom dimensions are: Somatization, Obsessive-Compulsive, Interpersonal Sensitivity, Depression, Anxiety, AngerHostility, Phobic Anxiety, Paranoid Ideation and Psychoticism. The Global Severity Index is a global index that measures overall mental distress and the cut-off $\mathrm{T}$-value for clinically significant overall mental distress is 60 [22].

To assess health-related quality of life, we applied the psychometrically well-validated German translation of 
the Medical Outcome Study Form (SF-36) [24], a 36item self-rating questionnaire that covers eight healthrelated domains. The domains are Physical Functioning, Pain, General Health, Vitality, Social Functioning, Mental Health, Role Physical, and, Role Emotional. The Role Physical is defined as the extent to which the physical condition impairs work or other everyday activities (e.g. achieving less than usual, limitation of types of activities, or difficulty in carrying out certain activities). The Role Emotional is defined as the extent to which emotional problems impair work or other everyday activities.

Each domain yields a score ranging from 0 to 100 (best). In the vast majority of the published studies, the internal-consistency data of the SF-36 exceed 0.8 [24].

\section{Statistical analyses}

Descriptive statistics were produced based on demographic, treatment-related and psychometric data (SCL90-R, SF-36) and are presented as mean and standard deviation (SD) and median and range. The psychometric data of the SF-36 scores were not normally distributed as shown by the Kolmogorov-Smirnov Test. We therefore applied the non-parametric Mann-Whitney-U test to test differences between patients with or without a high degree of overall mental distress and the nonparametric Wilcoxon Test to compare transplantation recipients without a high degree of overall mental distress with healthy controls matched by age and gender. All statistic tests were two-tailed, with significance set at $\mathrm{p}<0.05$. In case of multiple comparisons, an alpha adjustment (Bonferroni) was used and $\mathrm{p}$ values $<0.006$ were considered significant.

All statistical analyses were performed with SPSS 18.0 for Windows (SPSS; Chicago, IL).
The study was approved by the Institutional Review Board of the Ludwig-Maximilians-University of Munich. Data protection met the standards set by German law. All persons gave their informed consent prior to their inclusion in the study.

\section{Results}

\section{Sociodemographic characteristics}

All 123 participants (69.1\% men, 30.9\% women) were Caucasian, and the mean age was 52.6 ( $\mathrm{SD}=11.6$; $\mathrm{Me}$ dian: 57.0) years.

Respondents with complete data were similar to those lost for refusal and untracebility on the sociodemographic and treatment parameters.

Table 1 summarizes the pre-transplantation clinical characteristics of the whole sample.

Table 2 shows the post-transplantation sociodemographic characteristics of patients.

\section{Psychiatric morbidity before transplantation}

Before transplantation the psychometric observer-rating scale TERS was performed on all transplantation candidates, and the following psychiatric diagnoses were recorded: alcoholism, abstinent at the time of psychiatric assessment (2.4\%), alcohol abuse, abstinent at the time of psychiatric assessment (7.4\%), adjustment disorder (17.2\%), substance abuse (opiate, benzodiazepine) (4.9\%), dysthymia (0.8\%) and obsessive-compulsive disorder $(0.8 \%)$. These diagnoses have been based on a psychiatric clinical interview.

\section{Overall mental distress after solid-organ transplantation} After transplantation 39 (31.7\%) recipients had clinically significant overall mental distress as measured on the Global Severity Index of the SCL-90-R (SCL-90-R cut-

Table 1 Indication for transplant

\begin{tabular}{|c|c|c|}
\hline Heart & Liver & Lung/heart and lung \\
\hline$(n=60)$ & $(n=42)$ & $(n=21)$ \\
\hline Ischemic cardiomyopathy: & Alcoholic liver disease: & Emphysema/COPD: \\
\hline $34(56.7 \%)$ & $12(28.6 \%)$ & $6(28.6 \%)$ \\
\hline Dilatative cardiomyopathy: & Infectious hepatitis ${ }^{a}$ : & Pulmonary fibrosis: \\
\hline \multirow[t]{7}{*}{$26(43.3 \%)$} & $13(31 \%)$ & $7(33.3 \%)$ \\
\hline & Primary biliary cirrhosis: & Pulmonary hypertension: \\
\hline & $5(11.9 \%)$ & $3(14.3 \%)$ \\
\hline & Malignancy & Other ${ }^{d}$ : \\
\hline & $6(14.3 \%)$ & $5(23.8 \%)$ \\
\hline & Miscellaneous & \\
\hline & $6(14.3 \%)$ & \\
\hline
\end{tabular}

\footnotetext{
${ }^{a}$ Infectious hepatitis encompasses HBV-related and/or HCV-related liver diseases.

${ }^{b}$ Malignancy includes hepatocellular carcinoma and other hepatic malignancies.

'Miscellaneous comprises Wilson's disease, Budd-Chiari syndrome, fulminant hepatic failure, and cryptogenic cirrhosis.

d Other indications for lung transplant include lymphangioleiomyomatosis, cystic fibrosis, and congenital cystic adenomatoid malformation of the lung.
} 
Table 2 Posttransplantation sociodemographic characteristics

\begin{tabular}{|c|c|c|c|c|c|}
\hline \multirow[t]{2}{*}{ Category } & All patients & Heart & Liver & Lung/heart and lung & $p^{d}$ \\
\hline & $(n=123)$ & $(n=60)$ & $(n=42)$ & $(n=21)$ & \\
\hline \multicolumn{6}{|l|}{ Gender } \\
\hline Male & $85(69.1 \%)$ & $50(83.3 \% 9$ & $28(66.7 \%)$ & $7(33.3 \%)$ & $x^{2}=18.393 ; d f=2$ \\
\hline Female & 38 (30.9\%) & $10(16.7 \%)$ & $14(33.3 \%)$ & $14(66.7 \%)$ & $\mathrm{p}<0.001^{\mathrm{a}}$ \\
\hline \multicolumn{6}{|l|}{ Age } \\
\hline Mean (years) & 52.6 & 54.9 & 50.9 & 49.5 & \\
\hline SD & \pm 11.6 & \pm 11.2 & \pm 11.8 & \pm 11.2 & $p=0.038^{b}$ \\
\hline Median & 57.0 & 58.0 & 54.5 & 53.0 & \\
\hline \multicolumn{6}{|l|}{ Marital status } \\
\hline Single & $12(9.8 \%)$ & $5(8.3 \%)$ & $2(4.8 \%)$ & $5(23.8 \%)$ & $p=0.151^{c}$ \\
\hline Married & $93(75.6 \%)$ & 49 (81.7\%) & $31(73.8 \%)$ & $13(61.9 \%)$ & \\
\hline Widowed & $2(1.6 \%)$ & $1(1.7 \%)$ & $1(2.4 \%)$ & - & \\
\hline Divorced & $16(13 \%)$ & $5(8.3 \%)$ & $8(19 \%)$ & $3(14.3 \%)$ & \\
\hline \multicolumn{6}{|l|}{ Employment status } \\
\hline Full-time & $25(20.3 \%)$ & $11(18.3 \%)$ & $13(31.0 \%)$ & $1(4.8 \%)$ & $p=0.006^{c}$ \\
\hline Part-time/homeworker & $12(9.8 \%)$ & $4(6.7 \%)$ & $8(19 \%)$ & - & \\
\hline Unemployment & $4(3.3 \%)$ & $3(5 \%)$ & $1(2.4 \%)$ & - & \\
\hline Retired & $12(9.8 \%)$ & $9(15 \%)$ & $2(4.8 \%)$ & $1(4.8 \%)$ & \\
\hline Disabled from work due to health-related reasons & $70(56.9 \%)$ & $33(55 \%)$ & $18(42.9 \%)$ & $19(90.5 \%)$ & \\
\hline
\end{tabular}

$\mathrm{SD}=$ Standard deviation.

${ }^{a} X^{2}$ tests.

${ }^{b}$ Kruskal-Wallis one-way analysis of variance or ranks.

c Fisher's exact test.

${ }^{d}$ Statistical tests were performed to proof differences of probability or categorical distributions among the different kinds of transplantation (liver-, heart-, lungtransplantation).

off T-value for clinically significant overall mental distress: 60). The mean Global Severity Index score for the transplantation recipients with clinically significant overall mental distress was 70.6 ( $\mathrm{SD}=7.3$; Median: 70.0) and for those without clinically significant overall mental distress 46.3 (SD=7.4; Median: 47.5) [Mann-Whitney$\mathrm{U}=0.000 ; \mathrm{p}<0.001]$.

Reflecting the primary symptom dimensions of the SCL90-R, transplantation recipients with clinically significant overall mental distress mainly had significant values in the following dimensions: Obsessive-compulsive (92.3\%), Somatization (87.2\%), Anxiety (84.6\%), Depression (82.1\%) and Phobic Anxiety (69.2\%). Less frequent findings were high values in these dimensions: Psychoticism (61.5\%), Paranoid Ideation (59\%), Anger and Hostility (53.8\%) and Interpersonal Sensitivity (51.3\%).

No significant differences between transplantation recipients with clinically significant overall mental distress and those without were found in the following sociodemographic characteristics: age (Mann-Whitney$\mathrm{U}=1541.0 ; \mathrm{p}=0.598)$, gender $\left(\mathrm{x}^{2}=0.670 ; \mathrm{df}=1, \mathrm{p}=0.413\right)$, maritial status $\left(\mathrm{x}^{2}=1.7 ; \mathrm{df}=3, \mathrm{p}=0.636\right)$, years in education and/or vocational training (Mann-Whitney-U=1562.5; $\mathrm{p}=0.675$ ). Regarding employment status, transplantation recipients with clinically significant overall mental distress were less often employed than those without such symptomatology ( $\left.x^{2}=9.9 ; \mathrm{df}=1, \mathrm{p}=0.04\right)$.

No significant differences between patients with postoperative overall mental distress symptomatology and those without were found in the pre- and postoperative frequency of alcohol abuse (Fisher's exact test; $\mathrm{p}=0.585$ ).

Table 3 illustrates the pre- and postoperative frequency of alcohol abuse.

Transplantation recipients with overall mental distress more frequently take benzodiazepines after the surgical intervention. However, it needs to be mentioned that even before transplantation patients with postoperative overall mental distress symptomatology displayed a higher level of benzodiazepine consumption (Fisher's exact test; $\mathrm{p}<0.001$ ).

Table 4 shows the benzodiazepine consumption before and after transplantation.

\section{Overall mental distress and postoperative medical complications}

In the sample we studied, the occurrence of postoperative medical complications (e.g. bleeding, infections, cardio-vascular, rejection) did not significantly differ in 
Table 3 Pre- and postoperative frequency of alcohol abuse

\begin{tabular}{|c|c|c|c|c|c|c|c|}
\hline & \multicolumn{2}{|c|}{$\begin{array}{l}\text { No alcohol abuse before } \\
\text { and after SOT }\end{array}$} & \multicolumn{2}{|c|}{$\begin{array}{l}\text { Alcohol abuse } \\
\text { before SOT }\end{array}$} & \multicolumn{2}{|c|}{$\begin{array}{l}\text { Current alcohol } \\
\text { abuse after SOT }\end{array}$} & \multirow[t]{2}{*}{$\mathrm{p}$} \\
\hline & $\mathbf{n}$ & $\%$ & $\mathbf{n}$ & $\%$ & $\mathbf{n}$ & $\%$ & \\
\hline SOT recipients with high degree of overall mental distress & 28 & $71.8 \%$ & 9 & $23.1 \%$ & 2 & $5.1 \%$ & $p=0.585^{a}$ \\
\hline SOT recipients with low degree of overall mental distress & 67 & $79.8 \%$ & 14 & $16.7 \%$ & 3 & $3.6 \%$ & \\
\hline
\end{tabular}

${ }^{\text {a }}$ Fisher's exact test.

transplantation patients with postoperative overall mental distress from those without overall mental distress $\left(\mathrm{x}^{2}=3.202 ; \mathrm{df}=1, \mathrm{p}=0.074\right)$. Transplantation recipients with postoperative overall mental distress did not show acute rejections following transplantation more frequently than those without overall mental distress (Fisher's exact test; $\mathrm{p}=0.330$ ).

Table 5 presents the history of retransplantations.

Overall mental distress and the type of transplantation There was no significant difference in the frequency of overall mental distress after transplantation between patients with liver, heart, or lung transplantation $\left(\mathrm{X}^{2}=1.411 ; \mathrm{df}=2 ; \mathrm{p}=0.534\right)$.

Table 6 illustrates the overall mental distress symptomatology according to type of transplantation.

\section{Overall mental distress and posttransplant type of medication}

Patients with overall mental distress after transplantation did not differ at the time of exploration in their prescribed medication from those recipients without postransplant overall mental distress (tacrolimus, cyclosporine $\left[\mathrm{x}^{2}=3.362 ; \mathrm{df}=4 ; \mathrm{p}=0.499\right]$; steroids $\left.\left[\mathrm{x}^{2}=1.526 ; \mathrm{df}=1 ; \mathrm{p}=0.217\right]\right)$.

The level of adjustment in psychosocial functioning before transplantation and overall mental distress after transplantation

Transplantation recipients with clinically significant overall mental distress had significantly lower levels of adjustment in psychosocial functioning before transplantation than those without significant overall mental distress after transplantation as measured in the TERS
(Mann-Whitney-U=1255; $\mathrm{p}=0.033$ ). The mean TERS score before transplantation was $36.4(\mathrm{SD}=9.8)$ in the subgroup of transplantation recipients with clinically significant overall mental distress and $32.8(\mathrm{SD}=7.5)$ in transplantation recipients without significant overall mental distress.

No differences between patients with clinically significant postoperative overall mental distress symptomatology and those without were found in the preoperative frequency of psychiatric disorders (Fisher's exact test; $\mathrm{p}=0.237$ ).

Table 7 Preoperative frequency of psychiatric disorders.

\section{The level of adjustment in psychosocial functioning}

before transplantation and postoperative medical complications and acute rejection

Transplantation recipients with postoperative medical complication did not differ in the level of adjustment in psychosocial functioning before transplantation as measured by the TERS (Mann-Whitney-U: 1614.5, $\mathrm{p}=0.160$ ). However, transplant recipients with acute rejection had significantly lower TERS scores before transplantation, than those without rejection, indicating a lower level of adjustment in psychosocial functioning before transplantation (pretransplant TERS mean score in the subgroup of recipients with rejection: 33.28, pretransplant TERS mean score in the subgroup of recipients without rejection: 36.68; Mann-Whitney-U: 593.5, $\mathrm{p}=0.027)$.

\section{Health-related quality of life and overall mental distress after transplantation}

In comparison with those transplantation recipients without clinically significant overall mental distress,

Table 4 Benzodiazepine consumption before and after transplantation

\begin{tabular}{|c|c|c|c|c|c|c|c|}
\hline & \multicolumn{2}{|c|}{$\begin{array}{l}\text { No benzo-diazepine } \\
\text { consumption before } \\
\text { and after SOT }\end{array}$} & \multicolumn{2}{|c|}{$\begin{array}{l}\text { Benzodiazepine } \\
\text { consumption before } \\
\text { SOT }\end{array}$} & \multicolumn{2}{|c|}{$\begin{array}{l}\text { Present benzo- } \\
\text { diazepine } \\
\text { consumption after } \\
\text { SOT }\end{array}$} & \multirow[t]{2}{*}{$p$} \\
\hline & $\mathbf{n}$ & $\%$ & $\mathbf{n}$ & $\%$ & $\mathbf{n}$ & $\%$ & \\
\hline SOT recipients with high degree of overall mental distress & 24 & $61.5 \%$ & 5 & $12.8 \%$ & 10 & $25.6 \%$ & $p<0.001^{a}$ \\
\hline SOT recipients with low degree of overall mental distress & 77 & $91.7 \%$ & 1 & $1.2 \%$ & 6 & $7.1 \%$ & \\
\hline
\end{tabular}


Table 5 The history of retransplantations of SOT recipients

\begin{tabular}{|c|c|c|c|c|c|c|c|}
\hline & \multicolumn{2}{|c|}{$\begin{array}{l}\text { No } \\
\text { retransplantation }\end{array}$} & \multicolumn{2}{|c|}{$\begin{array}{l}\text { One } \\
\text { retransplantation }\end{array}$} & \multicolumn{2}{|c|}{$\begin{array}{l}\text { Two } \\
\text { retransplantations }\end{array}$} & \multirow[t]{2}{*}{$\mathrm{p}$} \\
\hline & $\mathrm{n}$ & $\%$ & $\mathrm{n}$ & $\%$ & $\mathrm{n}$ & $\%$ & \\
\hline SOT recipients with high degree of overall mental distress & 37 & $94.9 \%$ & 1 & $2.6 \%$ & 1 & $2.6 \%$ & $p=0.330^{a}$ \\
\hline SOT recipients with low degree of overall mental distress & 79 & $94.0 \%$ & 5 & $6 \%$ & 0 & $0 \%$ & \\
\hline
\end{tabular}

transplantation recipients suffering from overall mental distress displayed significant impairments in all healthrelated quality of life SF-36 domains: Physical Functioning, Role Physical, Pain, General Health, Vitality, Social Functioning, Role Emotional and Mental Health.

Table 8 shows the health-related quality of life SF-36 domains according to overall mental distress.

Compared with healthy controls matched by age and gender, transplantation recipients without significant overall mental distress showed impairments in some health-related quality of life SF-36 domains: Physical Functioning (Wilcoxon-Z=-6.239, $\mathrm{p}<0.001$ ), Role Physical

(Wilcoxon-Z=-5.115, $\mathrm{p}<0.001$ ), Pain (Wilcoxon $-Z=-3.780$, $\mathrm{p}<0.001$ ), General Health (Wilcoxon $-Z=-3.009, \mathrm{p}<0.001$ ), Vitality (Wilcoxon-Z=-3.060, $\mathrm{p}=0.002$ ) and Social Functioning (Wilcoxon-Z $=-3.338, \mathrm{p}=0.001$ ).

\section{The level of adjustment in psychosocial functioning before transplantation and health-related quality of life after transplantation}

A Spearman rank correlations between pretansplant TERS scores and postoperative quality of life SF-36 domains scores showed that a low level of adjustment in psychosocial functioning before transplantation (indicated by higher pretansplant TERS scores) is significant negatively correlated with posttransplant health-related quality of life in the following SF-36 domains: Vitality $\left(r_{s}=-0.239, p=0.009\right)$, Role Emotional $\left(r_{s}=-0.239, p=0.009\right)$, Social Functioning $\left(\mathrm{r}_{\mathrm{s}}=-0.182, \mathrm{p}=0.046\right)$, and Mental Health $\left(r_{s}=-0.325, p<0.0001\right)$. In addition a trend of a negative correlation between high pretansplant TERS scores and pottransplant low health-related quality of life was observed in the SF-36 domains: Role emotional $\left(\mathrm{r}_{\mathrm{s}}=-0.176, \mathrm{p}=0.055\right)$ and Pain $\left(r_{s}=-0.157, p=0.086\right)$. No significant correlations between pretansplant TERS scores and pottransplant health-related quality of life were detected in the SF-36 domains Physical Functioning $\left(\mathrm{r}_{\mathrm{s}}=-0.069, \mathrm{p}=0.453\right)$ and General Health $\left(\mathrm{r}_{\mathrm{s}}=-0.131, \mathrm{p}=0.153\right)$.

\section{Discussion}

\section{Overall mental distress}

In spite of great advances in transplantation surgery and constant improvement in surgical techniques, tissue matching, organ preservation and patient selection, many patients display symptoms of mental distress and psychiatric morbidity [1-4,6,8-10]. However, up to now there have only been a few empirical findings on the prevalence of overall mental distress in transplantation recipients [25-27].

In our study, a large number $(n=39$ [31.7\%]) of transplantation recipients displayed clinically significant overall mental distress independent of prescribed posttransplant medication (tacrolimus, cyclosporine, steroids), and in the SCL-90-R obsessive-compulsive symptoms (92.3\%), somatization symptoms (87.2\%), anxiety symptoms (84.6\%), depression symptoms (82.1\%) and phobic anxiety symptoms $(69.2 \%)$ were a frequent finding.

Obsessive-compulsive symptoms could be regarded as thoughts that are repeated reminders of the transplantation and the subsequent stay in the intensive care unit. Concentration difficulties and an impaired ability to work are also shown in this SCL-90-R dimension. Furthermore, it could be hypothesized that the postransplant necessity for being very accurate in taking the prescribed medication to avoid rejections may aggravate obsessive-compulsive symptoms. Intrusive memories are also frequently mentioned in other studies as posttraumatic symptoms after transplantation [28]. For example, in an orthotopic liver transplantation study by Rothenhäusler et al. [10], 2.7\% suffered from full posttraumatic stress disorder and $16 \%$ from partial posttraumatic stress disorder. In another study by Favaro et al.

Table 6 Overall mental distress according to type of transplantation

\begin{tabular}{|c|c|c|c|c|c|c|c|}
\hline & \multicolumn{2}{|c|}{$\begin{array}{l}\text { Liver } \\
\text { transplantation }\end{array}$} & \multicolumn{2}{|c|}{$\begin{array}{l}\text { Heart } \\
\text { transplantation }\end{array}$} & \multicolumn{2}{|c|}{$\begin{array}{l}\text { Lung } \\
\text { transplantation }\end{array}$} & \multirow[t]{2}{*}{$\mathrm{p}$} \\
\hline & $\mathrm{n}$ & $\%$ & $\mathrm{n}$ & $\%$ & $\mathrm{n}$ & $\%$ & \\
\hline SOT recipients with high degree of overall mental distress & 15 & $35.7 \%$ & 16 & $26.7 \%$ & 8 & $38.1 \%$ & $x^{2}=1.411 ; d f=2 ; p=0.534^{a}$ \\
\hline SOT recipients with low degree of overall mental distress & 27 & $64.3 \%$ & 44 & $73.3 \%$ & 13 & $61.9 \%$ & \\
\hline
\end{tabular}




\begin{tabular}{|c|c|c|c|c|c|}
\hline & \multicolumn{2}{|c|}{$\begin{array}{l}\text { No preoperative psychiatric } \\
\text { disorder }\end{array}$} & \multicolumn{2}{|c|}{$\begin{array}{l}\text { Preoperative psychiatric } \\
\text { disorder }\end{array}$} & \multirow[t]{2}{*}{$\mathrm{p}$} \\
\hline & $\mathrm{n}$ & $\%$ & $\mathbf{n}$ & $\%$ & \\
\hline SOT recipients with high degree of overall mental distress & 32 & $82.1 \%$ & 7 & $17.9 \%$ & $p=0.237^{a}$ \\
\hline SOT recipients with low degree of overall mental distress & 76 & $90.5 \%$ & 8 & $9.5 \%$ & \\
\hline
\end{tabular}

[29], the estimated frequency of transplantation-related posttraumatic stress disorder after heart transplantation was $12 \%$.

Somatization symptoms could be interpreted on the one hand as greater body awareness after transplantation, while on the other hand they could reflect increased selfmonitoring of the body due to traumatic illness and transplantation experiences.

Depressive and anxiety symptomatologies are a frequent finding after transplantation and have been reported in numerous studies [4,6,8-10,13,30,31].

Deficits in interpersonal sensitivity (51.3\%) as measured in the SCL-90-R subscale interpersonal sensitivity are a less frequent finding in our study's patients and seem to show the physical vulnerability and insecurity remaining after the life-threatening experiences of illness and transplantation. The physical impairments and resulting feelings of low self-confidence could therefore cause of withdrawal from social life. In the case of transplantation recipients the psychoticism subscale of the SCL-90-R describes rather the isolation and the feeling of depersonalization after transplantation and should not be primarily interpreted as measurement of psychotic symptoms. Such symptoms are reported by $61.5 \%$. Paranoid ideation $(59 \%)$ in the SCL-90-R reflect the sense of inferiority and mistrust after transplantation, and the primary symptom dimension Anger and Hostility (53.8\%) characterizes the irritability and unbalance in many transplantation recipients.

Regarding our results it needs to be mentioned that transplantation candidates with low levels of adjustment in psychosocial functioning before transplantation are at higher risk of developing overall mental distress symptomatology after transplantation, and the incidence of overall mental distress is independent of type of transplantation and postoperative medical complications. However, transplant recipients with acute rejection have significantly lower TERS scores before transplantation than those without rejection, indicating a lower level of adjustment in psychosocial functioning before transplantation. Furthermore, no significant differences between patients with postoperative overall mental distress symptomatology and those without were found in the pre- and postoperative frequency of alcohol abuse. However, transplantation recipients with overall mental distress displayed a higher level of benzodiazepine consumption before and after the surgical intervention.

\section{Overall mental distress and health-related quality of life}

Health-related quality of life is an important measure of outcome after transplantation and in recent years, several studies have demonstrated that transplantation has beneficial effects on quality of life for the majority of patients, both in intermediate and in longterm outcomes $[10,32,33]$. However, impairments in health-related quality of life have been diagnosed in transplantation recipients with some psychiatric disorders (e.g. anxiety and affective disorders, posttraumatic stress disorder) after transplantation [25-28,33-35]. In this present study even transplantation recipients without overall mental distress display more impairments in some health-related quality of life domains than healthy controls matched by age and gender. It is recognised that overall mental distress impairs health-related quality of life and life satisfaction even in people with overall good health. Therefore a major aim of the present study was to explore if overall mental distress in solid-organ transplantation recipients is strongly associated with massive additional impairments to health-related quality of life. Indeed the transplantation recipients with overall mental distress examined in this study had a lower health-related quality of life compared with transplantation recipients without overall mental distress as shown by impairments in all health-related quality of life SF-36 domains.

Furthermore, a low level of adjustment in psychosocial functioning before transplantation (indicated by higher pretansplant TERS scores) was significantly negatively correlated with posttransplant health-related quality of life in the SF-36 domains Vitality, Role Emotional, Social Functioning, and Mental Health. In conclusion our results suggest that overall mental distress in solid-organ transplantation recipients is strongly associated with massive additional impairments to health-related quality of life. These results allow for the hypotheses that overall mental distress has adverse health effects that impair coping with activities in daily life, and/or that transplantation recipients with overall mental distress symptoms already display greater health impairments as such and not just after the transplantation. 
Table 8 HRQOL SF-36 subtests for SOT recipients with high degree of overall mental distress and SOT recipients with low degree of overall mental distress

\begin{tabular}{|c|c|c|c|c|}
\hline & $\begin{array}{l}\text { SOT recipients with high degree of overall } \\
\text { mental distress }\end{array}$ & $\begin{array}{l}\text { SOT recipients with low degree of overall } \\
\text { mental distress }\end{array}$ & $\begin{array}{l}\text { Mann- } \\
\text { Whitney-U }\end{array}$ & $p$ \\
\hline \multirow{5}{*}{$\begin{array}{l}\text { Physical } \\
\text { Functioning }\end{array}$} & Mean: 51.3 & Mean: 70.5 & \multirow[t]{5}{*}{894.00} & \multirow[t]{5}{*}{$\mathrm{p}<0.001^{\mathrm{a}}$} \\
\hline & SD: \pm 27.6 & SD: \pm 25.9$)$ & & \\
\hline & Median: 57.5 & Median: 80.0 & & \\
\hline & Minimum: 0 & Minimum: 0 & & \\
\hline & Maximum: 95 & Maximum: 100 & & \\
\hline \multirow[t]{5}{*}{ Role Physical } & Mean: 31.6 & Mean: 63.1 & \multirow[t]{5}{*}{927.50} & \multirow[t]{5}{*}{$\mathrm{p}<0.001^{\mathrm{a}}$} \\
\hline & SD: \pm 37.1 & SD: \pm 43.4 & & \\
\hline & Median: 12.5 & Median: 100.0 & & \\
\hline & Minimum: 0 & Minimum: 0 & & \\
\hline & Maximum: 100 & Maximum: 100 & & \\
\hline \multirow[t]{5}{*}{ Pain } & Mean: 43.2 & Mean: 73.7 & \multirow[t]{5}{*}{701.00} & \multirow[t]{5}{*}{$p<0.001$} \\
\hline & SD: \pm 26.3 & SD: \pm 28.3 & & \\
\hline & Median: 41.0 & Median: 74.0 & & \\
\hline & Minimum: 0 & Minimum: 0 & & \\
\hline & Maximum: 100 & Maximum: 100 & & \\
\hline \multirow[t]{5}{*}{ General Health } & Mean: 42.2 & Mean: 63.5 & \multirow[t]{5}{*}{652.00} & \multirow[t]{5}{*}{$\mathrm{p}<0.001^{\mathrm{a}}$} \\
\hline & SD: \pm 17.8 & SD: \pm 20.3 & & \\
\hline & Median: 41 & Median: 62.0 & & \\
\hline & Minimum: 0 & Minimum: 0 & & \\
\hline & Maximum: 82 & Maximum. 100 & & \\
\hline \multirow[t]{5}{*}{ Vitality } & Mean: 40.7 & Mean: 60.3 & \multirow[t]{5}{*}{719.00} & \multirow[t]{5}{*}{$\mathrm{p}<0.001^{\mathrm{a}}$} \\
\hline & SD: \pm 17.8 & SD: \pm 20.09 & & \\
\hline & Median: 45.0 & Median: 60.0 & & \\
\hline & Minimum: 5 & Minimum: 0 & & \\
\hline & Maximum: 80 & Maximum: 100 & & \\
\hline \multirow{5}{*}{$\begin{array}{l}\text { Social } \\
\text { Functioning }\end{array}$} & Mean:65.8 & Mean: 86.7 & \multirow[t]{5}{*}{701.00} & \multirow[t]{5}{*}{$\mathrm{p}<0.001^{\mathrm{a}}$} \\
\hline & SD: \pm 20.9 & SD: \pm 19.7 & & \\
\hline & Median: 62.5 & Median: 100.0 & & \\
\hline & Minimum: 25 & Minimum: 0 & & \\
\hline & Maximum: 100 & Maximum: 100 & & \\
\hline \multirow[t]{5}{*}{ Role Emotional } & Mean: 53.5 & Mean: 85.8 & \multirow[t]{5}{*}{930.00} & \multirow[t]{5}{*}{$\mathrm{p}<0.001^{\mathrm{a}}$} \\
\hline & SD: \pm 44.2 & SD: \pm 31.9$)$ & & \\
\hline & Median: 50.0 & Median: 100.0 & & \\
\hline & Minimum: 0 & Minimum: 0 & & \\
\hline & Maximum: 100 & Maximum: 100 & & \\
\hline \multirow[t]{5}{*}{ Mental Health } & Mean: 59.9 & Mean: 79.8 & \multirow[t]{5}{*}{578.00} & \multirow[t]{5}{*}{$\mathrm{p}<0.001^{\circ}$} \\
\hline & SD: \pm 19.0 & SD: \pm 16.3$)$ & & \\
\hline & Median: 60.0 & Median: 84.0 & & \\
\hline & Minimum: 12 & Minimum: 0 & & \\
\hline & Maximum: 96 & Maximum: 100 & & \\
\hline
\end{tabular}

SOT: solid-organ transplantation.

${ }^{a}$ Mann-Whitney-U-test. 


\section{Limitations}

There are several limitations to our study. First, the format of the study is a retrospective follow-up. Further, the small group sizes of the organ-subgroups may be a limitation that needs to be mentioned. Regarding the statistical analysis the different organ-subgroups have been considered as a whole group, in spite of their diverse characteristics (e.g. development of organ insufficiency, different waiting times, different availability of assisting devices). However, several studies have shown that a common data interpretation is possible due to the homogeneously traumatic experiences caused by the solid-organ transplantation followed by intensive care unit treatment [28]. All participating participants were Caucasian. As a limitation some ethnic groups may have different interpretations of the symptoms.

Finally, our observations should be confirmed in studies with higher sample sizes to gain a clearer insight into the degree of overall mental distress in transplantation recipients.

\section{Conclusions}

Transplantation recipients may face major transplantationand treatment-related overall mental distress and impairments to their health-related quality of life. Further, overall mental distress is a high-risk factor in intensifying impairments to patients' overall quality of life.

The results of our study indicate that a pretransplant evaluation based on the Transplant Evaluation Rating Scale can help in indicating patients who are at high risk of posttransplant mental distress and impairments in health-related quality of life. Therefore pretransplant diagnostic screening based on the Transplant Evaluation Rating Scale may facilitate postransplant psychosocial support for these patients, who could be given specialized help in advance of transplantation. Putatively this would also have an impact on the transplant recipients' postoperative health-related quality of life.

In conclusion we advise that as part of routine clinical care, an early and comprehensive diagnosis and bio- and psychosocial therapeutic treatment of transplantation patients with clinically significant concomitant overall mental distress to be carried out, so that their overall mental distress symptomatology can be treated rapidly and their quality of life can be improved. In the future the development of new specific therapeutic strategies to reduce overall mental distress are desirable.

\section{Abbreviations \\ SCL-90-R: SCL-90-R Symptom Check List; SD: Standard deviation; SF- 36: Medical Outcome Study Form SF-36; TERS: Transplant Evaluation Rating Scale (TERS).}

\section{Competing interests}

The authors declare that they have no competing interests.

\section{Authors' contributions}

AB: participated in data analysis; participated in the writing of the paper. TK: participated in research design; participated in the performance of the research. H-BR: participated in research design; participated in the performance of the research, participated in the writing of the paper. All authors read and approved the final manuscript.

\section{Authors' information}

Department and Institution where work was performed: Psychiatric Consultation-Liaison Service, Department of Psychiatry, LudwigMaximilians-University Medical School and Klinikum Grosshadern, Munich, Germany.

\section{Author details}

'Department of Psychiatry, University of Medicine of Graz, Auenbruggerplatz 31, 8036, Graz, Austria. ${ }^{2}$ Department of Psychiatry, Ludwig-Maximilians University of Munich, Nußbaumstraße 7, 80336, Munich, Germany.

Received: 3 October 2012 Accepted: 4 February 2013 Published: 8 February 2013

\section{References}

1. Freeman AM 3rd, Westphal JR, Davis LL, Libb JW: The future of organ transplant psychiatry. Psychosomatics 1995, 36(5):429-437.

2. Collis I, Burroughs A, Rolles K, Lloyd G: Psychiatric and social outcome of liver transplantation. Br J Psychiatry 1995, 166(4):521-524.

3. Commander M, Neuberger J, Dean C: Psychiatric and social consequences of liver transplantation. Transplantation 1992, 53(5):1038-1040.

4. Fukunishi I, Sugawara Y, Takayama T, Makuuchi M, Kawarasaki H, Kita Y, Aikawa A, Hasegawa A: Psychiatric problems in living-related transplantation (I): incidence rate of psychiatric disorders in livingrelated transplantation. Transplant Proc 2002, 34(7):2630-2631.

5. Baranyi A, Rösler D, Rothenhäusler HB: Stress symptoms and healthrelated quality of life in patients after orthotopic liver transplantation. Z Psychosom Med Psychother 2012, 58(4):417-428.

6. Kizilisik AT, Shokouh-Amiri MH, Tombazzi CR, Desmukh S, Grewal HP, Vera SR, Gaber AO: Psychiatric complications after liver transplantation. Transplant Proc 2001, 33(7-8):3697.

7. Olbrisch ME, Benedict SM, Ashe K, Levenson JL: Psychological assessment and care of organ transplant patients. J Consult Clin Psychol 2002, 70(3):771-783.

8. Potts SG: Transplant psychiatry. J R Coll Physicians Edinb 2009, 39(4):331-336.

9. Rothenhausler HB, Ehrentraut S, Kapfhammer HP: Psychosocial screening and selection of candidates for liver transplantation. Psychother Psychosom Med Psychol 2003, 53(9-10):364-375.

10. Rothenhausler HB, Ehrentraut S, Kapfhammer HP, Lang C, Zachoval R, Bilzer M, Schelling G, Gerbes AL: Psychiatric and psychosocial outcome of orthotopic liver transplantation. Psychother Psychosom 2002, 71(5):285-297.

11. Sears SF Jr, Marhefka SL, Rodrigue JR, Campbell C: The role of patients' ability to pay, gender, and smoking history on public attitudes toward cardiac transplant allocation: an experimental investigation. Health Psychol 2000, 19(2):192-196.

12. Duffy JP, Kao K, Ko CY, Farmer DG, McDiarmid SV, Hong JC, Venick RS, Feist S, Goldstein L, Saab S, Hiatt JR, Busuttil RW: Long-term patient outcome and quality of life after liver transplantation: analysis of 20-year survivors. Ann Surg 2010, 252(4):652-661.

13. Saeed I, Rogers C, Murday A, Steering Group of the UK Cardiothoracic Transplant Audit: Health-related quality of life after cardiac transplantation: results of a UK National Survey with Norm-based Comparisons. J Heart Lung Transplant 2008, 27(6):675-681.

14. Santana MJ, Feeny D, Ghosh S, Nador RG, Weinkauf J, Jackson K Schafenacker M, Zuk D, Hubert G, Lien D: The construct validity of the health utilities index mark 3 in assessing health status in lung transplantation. Health Qual Life Outcomes 2010, 8:110.

15. Nicholas DB, Otley AR, Taylor R, Dhawan A, Gilmour S, Ng VL: Experiences and barriers to Health-Related Quality of Life following liver transplantation: a qualitative analysis of the perspectives of pediatric patients and their parents. Health Qual Life Outcomes 2010, 8:150.

16. Fiebiger W, Mitterbauer C, Oberbauer R: Health-related quality of life outcomes after kidney transplantation. Health Qual Life Outcomes 2004, 2:2. 
17. Bevans MF, Mitchell SA, Barrett AJ, Bishop M, Childs R, Fowler D, Krumlauf M, Prince P, Shelburne N, Wehrlen L: Function, adjustment, quality of life and symptoms (FAQS) in allogeneic hematopoietic stem cell transplantation (HSCT) survivors: a study protocol. Health Qual Life Outcomes 2011, 9:24.

18. Doctor JN, Zoellner LA, Feeny NC: Predictors of health-related quality-oflife utilities among persons with posttraumatic stress disorder. Psychiatr Serv 2011, 62(3):272-277.

19. Schelling G, Richter M, Roozendaal B, Rothenhausler HB, Krauseneck $T$, Stoll C, Nollert G, Schmidt M, Kapfhammer HP: Exposure to high stress in the intensive care unit may have negative effects on health-related quality-of-life outcomes after cardiac surgery. Crit Care Med 2003, 31(7):1971-1980.

20. Schelling G, Stoll C, Kapfhammer HP, Rothenhausler HB, Krauseneck T, Durst $\mathrm{K}$, Haller M, Briegel J: The effect of stress doses of hydrocortisone during septic shock on posttraumatic stress disorder and health-related quality of life in survivors. Crit Care Med 1999, 27(12):2678-2683.

21. Twillman RK, Manetto C, Wellisch DK, Wolcott DL: The transplant evaluation rating scale. A revision of the psychosocial levels system for evaluating organ transplant candidates. Psychosomatics 1993, 34(2):144-153.

22. Derogatis LR, CPA: Confirmation of the dimensional structure of the SCL90: a study in construct validation. J Clin Psychol 1977, 33:981-989.

23. Derogatis LR, Lipman RS, Covi L: SCL-90: an outpatient psychiatric rating scale-preliminary report. Psychopharmacol Bull 1973, 9(1):13-28.

24. Stewart AL, Hays RD, Ware JE Jr: The MOS short-form general health survey. Reliability and validity in a patient population. Med Care 1988, 26(7):724-735.

25. Telles-Correia D, Barbosa A, Mega I, Barroso E, Monteiro E: Psychiatric and psychosocial predictors of medical outcome after liver transplantation: a prospective, single-center study. Transplant Proc 2011, 43(1):155-157.

26. Noma S, Hayashi A, Uehara M, Uemoto S, Murai T: Comparison between psychosocial long-term outcomes of recipients and donors after adult-toadult living donor liver transplantation. Clin Transplant 2011, 25(5):714-720.

27. Kugler C, Geyer S, Gottlieb J, Simon A, Haverich A, Dracup K: Symptom experience after solid organ transplantation. J Psychosom Res 2009, 66(2):101-110.

28. Kollner V, Schade I, Maulhardt T, Maercker A, Joraschky P, Gulielmos V: Posttraumatic stress disorder and quality of life after heart or lung transplantation. Transplant Proc 2002, 34(6):2192-2193.

29. Favaro A, Gerosa G, Caforio AL, Volpe B, Rupolo G, Zarneri D, Boscolo S, Pavan C, Tenconi E, D'Agostino C, Moz M, Torregrossa G, Feltrin G, Gambino A, Santonastaso P: Posttraumatic stress disorder and depression in heart transplantation recipients: the relationship with outcome and adherence to medical treatment. Gen Hosp Psychiatry 2011, 33(1):1-7.

30. Corruble E, Barry C, Varescon I, Falissard B, Castaing D, Samuel D: Depressive symptoms predict long-term mortality after liver transplantation. J Psychosom Res 2011, 71(1):32-37.

31. Fusar-Poli P, Matteo L, de Luca M, Politi P, Cortesi M, Carboni V: Anxiety and depression after lung transplantation: mirtazapine as a first-choice agent? J Psychosom Res 2007, 62(1):101.

32. Dew MA, Kormos RL, Winowich S, Harris RC, Stanford EA, Carozza L, Griffith $B P$ : Quality of life outcomes after heart transplantation in individuals bridged to transplant with ventricular assist devices. J Heart Lung Transplant 2001, 20(11):1199-1212.

33. Goetzmann L, Klaghofer R, Wagner-Huber R, Halter J, Boehler A, Muellhaupt B, Schanz U, Buddeberg C: Psychosocial vulnerability predicts psychosocial outcome after an organ transplant: results of a prospective study with lung, liver, and bone-marrow patients. J Psychosom Res 2007, 62(1):93-100.

34. Bownik H, Saab S: Health-related quality of life after liver transplantation for adult recipients. Liver Transp/ 2009, 15(Suppl 2):S42-S49.

35. Strauss B, Thormann T, Strenge H, Biernath E, Foerst U, Stauch C, Torp U, Bernhard A, Speidel H: Psychosocial, neuropsychological and neurological status in a sample of heart transplant recipients. Qual Life Res 1992, 1(2):119-128.

doi:10.1186/1477-7525-11-15

Cite this article as: Baranyi et al:: Overall mental distress and healthrelated quality of life after solid-organ transplantation: results from a retrospective follow-up study. Health and Quality of Life Outcomes 2013 11:15.

\section{Submit your next manuscript to BioMed Central and take full advantage of:}

- Convenient online submission

- Thorough peer review

- No space constraints or color figure charges

- Immediate publication on acceptance

- Inclusion in PubMed, CAS, Scopus and Google Scholar

- Research which is freely available for redistribution 